\title{
Acute bronchiolitis in infancy: treatment and prognosis
}

Acute bronchiolitis is the most common severe lower respiratory tract infection of infancy. About $2 \%$ of all babies born in the previous 12 months will be admitted to hospital with the condition.' Although the clinical picture can be produced by various viruses, including influenza and parainfluenza virus and the adenoviruses, most cases, particularly during the winter epidemics, are due to infection with the respiratory syncytial virus.

There has been considerable and, to some extent, unresolved dispute about the features necessary for the diagnosis. There is a tendency, especially in North America, ${ }^{2}$ to apply the term to all babies who have signs of acute lower airways obstruction in infancy, particularly if the baby has previously been well. This grouping will inevitably include an appreciable number of babies with asthma. This can largely be avoided if the term is limited to babies who have tachypnoea, hyperinflation, and fine crepitations at some time during the course of the illness, ${ }^{3}$ after pneumonia and heart failure have been excluded by chest radiography. Although differentiating between acute bronchiolitis and infantile asthma currently has little, if any, influence on management, long term studies have shown that the outcome is different, and it is important if long term epidemiological studies are to be carried out that the diagnosis is refined as much as possible.

\section{Prognosis}

Although the infants look critically ill on presentation, with gross hyperinflation and recession and often with cyanosis and sometimes carbon dioxide retention, nearly all make what appears to be a dramatic and complete recovery within five to 10 days. There is, however, increasing evidence to show that acute bronchiolitis is associated with a considerable amount of morbidity persisting for many years.

\section{MORTALITY}

The mortality in babies who have previously been well

Address for reprint requests: Professor A D Milner, Department of Child Health, Queen's Medical Centre, Nottingham NG7 2UH. is fortunately low, less than $1 \%$ in most studies. Those who have significant pre-existing cardiorespiratory disease, such as those with severe congenital heart disease, ${ }^{4}$ bronchopulmonary dysplasia, or cystic fibrosis, and those who are immunosuppressed ${ }^{5}$ are at considerably increased risk and mortality in excess of $30 \%$ has been reported.

\section{CHRONIC BRONCHIOLITIS}

There are also a few babies, ${ }^{6}$ again less than $1 \%$, who fail to make the expected recovery and who have persisting respiratory distress with hyperinflation, crepitations with or without wheezing, oxygen dependency, feeding problems, and often failure to thrive lasting for many weeks or even months. Most of these babies have bronchiolitis due to specific adenovirus strains, particularly 7 and 21 ; but probably respiratory syncytial virus itself can produce this picture. At necropsy or lung biopsy the histological appearance is grossly abnormal with areas of hyperinflation and collapse and grossly abnormal small airways-hence the term obliterative bronchiolitis. Although most of these infants do eventually thrive and lose their oxygen dependence, some at least have persisting abnormalities and restriction of exercise tolerance even in later childhood. We do not yet know what the impact of this condition will be on respiratory reserve and decay in lung function in adult life.

\section{ABNORMAL AIR WAY LABILITY}

Several studies have shown that a high proportion of babies admitted to hospital with acute bronchiolitis will have subsequent attacks of coughing and wheezing associated with abnormal airway lability. Studies have shown that $75 \%$ of such babies will have symptoms of wheezing over the subsequent two years, and that the incidence of wheezing falls to $42 \%$ by the age of 5 years (MW Murray et al, unpublished findings) and to $22 \%$ by $8-10$ years. $^{8}$ Although response to treatment in the first year of life is predictably poor, these episodes of lower airway obstruction respond well to appropriate antiasthma treatment later on.

These children, however, differ from those with the 
classical asthma of early childhood in three interesting ways. Firstly, as already stated, they tend to lose their "asthma" symptoms relatively early in childhood. There is currently no information on what happens to them beyond the age of 10 and possibly some will have a recurrence of problems in adult life, as has been documented in long term prospective studies of childhood asthma.'

The second difference is that most controlled studies, particularly those of Pullan and $\mathrm{Hey}^{8}{ }^{8} \mathrm{Sims}$ and Gardner, ${ }^{10}$ and Mok and Simpson, ${ }^{11}$ have failed to show an increased incidence of atopy in children who have been admitted to hospital with acute bronchiolitis. Indeed, Pullan and Hey found a significant but inverse relation between a history of bronchiolitis and a positive skin test response. The reverse picture has emerged in a recent prospective study of children seen five and a half years after acute bronchiolitis in Nottingham (MW Murray et al, unpublished findings), but even in this group there was no significant relation between a history of atopy or a positive skin test response and persistence of symptoms, a very different pattern from that seen in classical childhood asthma.

The third difference has emerged from investigation of the family history of atopy and asthma. No difference was seen in the incidence of wheezing ${ }^{8}$ or diagnosed asthma in first degree relatives of index patients and controls. In an attempt to evaluate the contribution of genetic factors to the increase in bronchial responsiveness to methacholine that is seen after respiratory syncytial virus infection, Gurwitz et $a l^{2}$ tested the first degree relatives. They found that $33 \%$ of first degree relatives of hyperreactive index patients had a positive response to bronchial challenge. Unfortunately they did not test the first degree relatives of children without a positive response to methacholine, nor did they recruit a separate control group. This work therefore needs repeating.

These observations suggest that infection with respiratory syncytial virus is probably itself responsible for the abnormal airway lability that persists for five to 10 years after the attack. Interestingly, in adults upper respiratory infections due to respiratory syncytial virus may be associated with increased bronchial reactivity for several weeks after the illness. ${ }^{13}$ The pathological basis of increased airway lability after bronchiolitis in children is not known.

In the acute attack there is little doubt that the epithelium is damaged, creating a condition in which short term abnormalities of airway lability might be expected, similar to those in adults who have suffered severe influenzal infections. ${ }^{14}$ Possibly recurrent infections by other viruses are necessary to perpetuate the abnormal airway lability and, indeed, many of these children will wheeze only at times when they have upper respiratory tract infections and even in infancy $\overrightarrow{\vec{F}}$ may lose their bronchoconstrictor response to mist at times when they are free from infection. Interestingly, 등 one follow up study ${ }^{15}$ has shown that babies develop- $\frac{\bar{c}}{\bar{c}}$ ing acute bronchiolitis but not having symptoms of $\frac{\vec{\sigma}}{\widetilde{D}}$ sufficient severity to require admission to hospital $\cong$ suffered far fewer subsequent respiratory problems. ळ) An alternative explanation, that respiratory syncytial $\overrightarrow{0}$ virus bronchiolitis is selecting out those babies likely to $-\overrightarrow{-}$ develop asthma on the basis of an inherited tendency $\vec{\omega}$ to abnormal airway lability, ${ }^{16}$ is difficult to sustain. The lack of a significant association with personal or $\stackrel{x}{\times}$ family history of atopy militates against this hypothesis.

A further possibility relates to the observation by $\vec{\circ}$ Welliver $e t a l^{77}$ of low numbers of OKT8 positive cells in babies with acute bronchiolitis, suggesting defective $\vec{c}$ immune regulation during the acute illness. This change is associated with production of respiratory syncytial virus specific IgE in the nasopharynx. A further study by Welliver et $a l^{18}$ has related the $\vec{\bullet}$ magnitude of the virus specific IgE response to the number of subsequent wheezing attacks. The propensity to this immune response in infancy may be inherited. Its relation to other forms of IgE mediated disease and atopy is not yet known.

\section{PERSISTING SMALL AIR WAY DAMAGE}

A single study, on 23 children, ${ }^{19}$, suggests that small airway damage may persist and possibly lay the foundation for chronic bronchitis and emphysema in adult life. These children, who were 10 years old at the time of assessment, apparently had had no respiratory symptoms since their acute attack of bronchiolitis and $\underset{-}{x}$ the results of standard spirometry were entirely nor- $\frac{3}{3}$ mal. They tended, however, to have increased residual volumes, had an increase in their helium-air isovolume $\frac{3}{3}$ point on flow-volume measurements, and tended to have a low arterial oxygen tension. Unfortunately, these children had not been followed up prospectively $\frac{7}{0}$ and so possibly they had had respiratory problems early on. The children were not given any treatment ${ }_{\sigma}^{N}$ for asthma, so it is not possible to state whether these $\mathrm{N}$ changes were irreversible or represented a ventilation- $N$ perfusion abnormality secondary to mild underlying $\omega$ asthma. Finally, no control group had been recruited.? It is obviously of critical importance that these studies should be repeated to investigate whether respiratory $ळ$ syncytial virus does indeed leave permanent structural ${ }_{+}^{+}$ damage in the small airways, as it is at least possible $-{ }_{0}^{-}$ that the association between respiratory symptoms

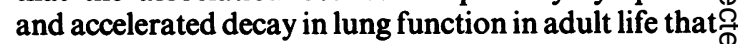
has been associated with respiratory problems in early음 childhood is in part related to acute bronchiolitis in? infancy. 
Management

MONITORING

Babies admitted to hospital with acute bronchiolitis are often in respiratory failure, sometimes with substantially raised arterial carbon dioxide tensions, and a fivefold or greater increase in the work of breathing. ${ }^{20}$ These children may become exhausted and require ventilatory support, although they more commonly have to be intubated for apnoea. It is therefore extremely important that the babies are carefully monitored. This should include the use of heart rate and apnoea-respiration monitors along with close observation by the nursing staff.

\section{OXYGEN THERAPY}

Many of these babies are hypoxaemic and this may indeed be a factor leading to the increased incidence of apnoea. ${ }^{21}$ The babies can best be nursed in a semi prone position with sufficient added oxygen to relieve any hypoxaemia. The introduction of oxygen saturation monitors has greatly facilitated the identification and treatment of hypoxia.

\section{ANTIBIOTICS}

Antibiotics have often been given in the past on the assumption that, although the primary infecting agent is viral, secondary bacterial infection is likely to occur. There is, however, no evidence that babies who were previously well get secondary bacterial infection and nearly all make an excellent short term recovery without receiving even oral antibiotics. Nevertheless, it is not unreasonable for junior medical staff to start critically ill babies on antibiotic treatment as this condition in its early stages may be difficult to differentiate from acute staphylococcal pneumonia.

\section{BRONCHODILATOR DRUGS}

Bronchodilator drugs have quite reasonably been given for many years. As already stated, many of these babies will have subsequent attacks of coughing and wheezing, so that they merge with the childhood asthmatic population. Indeed, several studies have been set up in the hope that those likely to develop symptoms later could be identified by their response to appropriate bronchodilator treatment in the acute phase. Studies have consistently shown, however, that bronchodilator drugs such as isoprenaline, ${ }^{22}$ adrenaline, ${ }^{23}$ salbutamol, ${ }^{24}$ and theophylline ${ }^{25}$ have no influence on the degree of airways obstruction during the acute illness. A single study suggested that treatment with nebulised ipratropium bromide did significantly reduce the work of breathing. ${ }^{26} \mathrm{~A}$ subsequent double blind controlled trial, ${ }^{27}$ however, showed that active treatment had no influence on the rate of recovery, although the parents did seem to be able to identify those children who were receiving ipratropium bromide rather than saline.

\section{STEROIDS}

Corticosteroids have been given in the hope that they would reduce the inflammation in the lower airway and so shorten the course of the illness. Several large double blind studies ${ }^{28}$ have been carried out but all have failed to show any benefit other than relief of any pyrexia. Possibly treatment with oral steroids or indeed with appropriate inhaled steroids might influence the long term outcome, even if the acute episode is not significantly modified.

\section{MIST TREATMENT}

Mist treatment has been given in the past in the hope that this would help to clear the secretions and debris that block the small airways. There is now good evidence that giving particulate water from either a conventional or an ultrasonic nebuliser to babies with abnormal airway lability will actually induce bronchoconstriction lasting for $10-15$ minutes. ${ }^{29}$ The humidifying devices used in the past-that is, croupettes-were totally ineffective, raising the water content only to about $20 \mathrm{mg} / 1$, less than half that achieved by drawing air through the naries.

\section{PHYSIOTHERAPY}

Physiotherapy is also a popular form of treatment, again given in the hope that it will clear secretions from the airways. The single controlled study, ${ }^{30}$ carried out on 96 children admitted over two seasons, failed to show any benefit from physiotherapy, and indeed, there is some anecdotal evidence that babies may deteriorate rapidly during vigorous physiotherapy sessions with apnoea requiring intubation and subsequent respiratory support.

\section{ANTIVIRAL AGENTS}

There is now an antiviral agent, ribavirin, that is effective against respiratory syncytial virus. ${ }^{31}$ It is given as an aerosol with a device (SPAG) producing a fine mist with a median particle size of only $1.3 \mu \mathrm{m}$. The output of the nebuliser is fed into a headbox. The extent to which the ribavirin penetrates into the bronchioles in these babies is not known. The small particle size would suggest that at least some will penetrate deep into the lungs. The optimal time for treatment has also not been defined. In one study treatment that was given for only 12 hours produced less satisfactory results than when treatment was given for about 20 out of the 24 hours. ${ }^{32}$

Ribavirin given in this manner appears to be free of worrying side effects. When given orally in large doses it produces teratogenic changes in pregnant rodents ${ }^{33}$ but the amount taken up by medical and nursing staff 
caring for these babies appears to be negligible. Certainly there is too little in the blood to register even with highly sensitive assays. So far four double blind clinical trials have been published, assessing the effect of nebulised ribavirin and placebo on babies with acute bronchiolitis who had been previously well. $.^{32} 34-36$ In all four studies resolution of symptoms tended to occur more rapidly in babies receiving ribavirin than in controls, and in two studies oxygenation improved significantly with ribavirin treatment. ${ }^{34} 36$ In only one study, however, was elimination of virus from the respiratory tract accelerated and there was no evidence to suggest that treatment with ribavirin allowed the children to be discharged from hospital earlier. The studies are too small to detect any effect on mortality in these previously well babies. ${ }^{37}$

Two studies have been carried out in babies with pre-existing cardiopulmonary disease, a group of children with significantly increased mortality from bronchiolitis. In one study 33 treated patients were compared with 97 admitted during the same epidemic. The authors claimed that the ribavirin was associated with a more rapid resolution of symptoms, but as this was not a formal, controlled study interpretation of the results is difficult. ${ }^{38}$ In the one controlled trial in this group of patients there again appeared to be benefit from treatment within 24-48 hours, but happily no deaths occurred in either the treated or the control babies. ${ }^{39}$

In our current state of knowledge giving ribavirin, despite its cost, to babies who have severe pre-existing cardiorespiratory disease would seem reasonable, in the hope that it may prevent death in at least some. It is much more difficult, however, to justify giving it to babies who have been previously well, unless they become critically ill and require assisted ventilation. Ribavirin can then be introduced into the ventilator circuit, although this is not without its problems as ribavirin tends to build up in the circuit and cause the expiratory valves to stick unless special filters are inserted. If, however, ribavirin treatment during the acute phase can be shown to modify longer term morbidity, this recommendation will obviously have to be reconsidered. ${ }^{31}$

\section{PROPHYLAXIS}

As respiratory syncytial virus infections produce so much morbidity, several attempts have been made to produce a vaccine. Theoretically, this should not be a major problem as there are only two subtypes. The killed vaccine produced in the 1960 s certainly led to a good IGg response in healthy volunteers but when it was assessed in clinical trials the severity of the subsequent infection in those who had been immunised was increased rather than reduced ${ }^{40}$ There are now attempts to produce either a modified live vaccine that could be given either by injection or directly to the respiratory tract or to use genetic engineering to $\stackrel{?}{+}$ produce surface antigens that could be given with relative safety. As the babies who suffer most from $\frac{\overline{\bar{N}}}{\overline{0}}$ bronchiolitis are those less than 3 months of age, the $\frac{\sigma}{\vec{\sigma}}$ vaccine might even need to be given to mothers during $\propto$ the third trimester. In support of this is a paper $\stackrel{\infty}{\infty}$ indicating that high maternal respiratory syncytial $\overrightarrow{0}$ virus antibody titres have a protective effect in early infancy. ${ }^{41}$

Although acute bronchiolitis has so far proved unresponsive to a wide range of treatments, the $\vec{x}$ development of effective vaccines and antiviral agents + may dramatically alter this in the near future. If so, we may be able to reduce the incidence of asthma in early $\vec{\overrightarrow{ }}$ childhood and perhaps even reduce the frequency and severity of respiratory disease throughout life. Mean- $\vec{c}$ while acute bronchiolitis and its sequelae warrant careful study, as this is a setting in which asthma may well be caused largely by environmental rather than genetic factors.

\section{AD MILNER M MURRAY University Department of Child Health University Hospital Nottingham}

MM was funded by the Asthma Research Council.

\section{References}

1 Martin AJ, Gardner PS, McQuillin J. Epidemiology of respiratory viral infections among paediatric inpatients over a six year period in North East England. Lancet 0 1978;ii:1035-8.

2 McConnochie K. Bronchiolitis: what's in the name? Am JDis Child 1983;137:11-3.

3 Henry RL, Milner AD, Stokes GM. Bronchiolitis [letter]. Am J Dis Child 1983;137:805-6.

4 MacDonald NE, Hall CB, Suffin SC, Alexson C, Harris PJ, Manning JA. Respiratory syncytial viral infections in infants with congenital heart disease. $N$ Engl J Med $\triangle$ 1982;307:397-400.

5 Hall CB, Powell KR, MacDonald NE, et al. Respiratory syncytial viral infection in children with compromised 0 immune function. $N$ Engl J Med 1986;315:77-81. N

6 Hodges IGC, Milner AD, Groggins RC, Stokes GM.N Causes and management of bronchiolitis with chronic ${ }^{\omega}$ obstructive features. Arch Dis Child 1982;57:495-9. \%

7 Henry RL, Hodges IGC, Milner AD, Stokes GM. Respiratory problems two years after acute bronchiolitis in infancy. Arch Dis Child 1983;58:713-6.?

8 Pullan CR, Hey EN. Wheezing, asthma and pulmonary dysfunction 10 years after infection with respiratory syncytial virus in infancy. $\mathrm{Br}$ Med J 1982;284:1665-9.

9 Phelan PD. Does adult chronic obstructive lung disease $\stackrel{\mathrm{D}}{\mathrm{C}}$ really begin in childhood? Br J Dis Chest 1984;78:1-9. 응

10 Sims DG, Gardner PS, Weightman D, Turner MW, Soothill JF. Atopy does not predispose to RSV 
bronchiolitis or post bronchiolitic wheezing. $\mathrm{Br} \mathrm{Med} J$ 1981;282:2086-8.

11 Mok JYQ, Simpson H. Symptoms, atopy and bronchial reactivity after lower respiratory infection in infancy. Arch Dis Child 1984;59:299-305.

12 Gurwitz D, Mindorff C, Levison H. Increased incidence of bronchial reactivity in children with a history of bronchiolitis. J Ped 1981;98:551-5.

13 Hall W, Hall CB, Speers D. RSV infection in adults. Ann Intern Med 1978;88:203-5.

14 Hers JF, Mulder J. Pathology and pathogenesis of human influenza. Am Rev Respir Dis 1961;83:84-9.

15 McConnochie KM, Mark JD, McBride JT, et al. Normal pulmonary function measurements and airway reactivity in childhood after mild bronchiolitis. $J$ Ped 1985;107:54-8.

16 Rooney JC, Williams HE. The relationship between proved viral bronchiolitis and subsequent wheezing. J Pediatr 1971;79:744-7.

17 Welliver RC, Kaul TN, Sun M, Ogra PL. Defective regulation of immune responses in respiratory syncytial virus infection. J Immunol 1984;133:1925-30.

18 Welliver RC, Sun M, Rinaldo D, Ogra PL. Predictive value of respiratory syncytial virus-specific IgE responses for recurrent wheezing following bronchiolitis. J Pediatr 1986;109:776-80.

19 Kattan M, Keens TG, Lapierre J-G, Levison H, Bryan C, Reilly BJ. Pulmonary function abnormalities in symptom-free children after bronchiolitis. Pediatrics 1977;59:683-8.

20 Stokes GM, Milner AD, Groggins RC. Work of breathing, intra-thoracic pressure and clinical findings in a group of babies with bronchiolitis. Acta Paediatr Scand 1981;70:689-94.

21 Hall CB, Hall WJ. Clinical and physiological manifestations of bronchiolitis and pneumonia. Am J Dis Child 1979;133:798-802.

22 Phelan PD, Williams HE. Sympathomimetic drugs in acute viral bronchiolitis. Their effect on pulmonary resistance. Pediatrics 1969;44:493-7.

23 Lenney W, Milner AD. Alpha and beta adrenergic stimulants in bronchiolitis and wheezy bronchitis in children under 18 months of age. Arch Dis Child 1978;53:707-9.

24 Rutter N, Milner AD, Hiller EJ. Effect of bronchodilators on respiratory resistance in infants and young children with bronchiolitis and wheezy bronchitis. Arch Dis Child 1975;50:719-22.

25 Brooks LJ, Cropp GJA. Theophylline therapy in bronchiolitis. Am J Dis Child 1981;135:934-6.

26 Stokes GM, Milner AD, Hodges IGC, Henry RL,
Elphick MC. Nebulised therapy in acute severe bronchiolitis in infancy. Arch Dis Child 1983;58: 279-83.

27 Henry RL, Milner AD, Stokes GM. Ineffectiveness of ipratropium bromide in acute bronchiolitis. Arch Dis Child 1983;58:925-6.

28 Leer JA, Green JL, Heimlich EM, et al. Corticosteroid treatment in bronchiolitis. A controlled, collaborative study in 297 infants and children. Am J Dis Child 1969;117:495-503.

29 O'Callaghan C, Milner AD, Swarbrick A. Nebulised salbutamol does have a protective effect on airways in children under 1 year old. Arch Dis Child 1988;63: 479-83.

30 Webb MSC, Martin JA, Cartlidge PHT, Ng YK, Wright NA. Chest physiotherapy in acute bronchiolitis. Arch Dis Child 1985;60:1078-9.

31 Milner AD. Ribavirin and acute bronchiolitis in infancy. Br Med J 1988;297:998-9.

32 Taber LH, Knight V, Gilbert BE, et al. Ribavirin aerosol treatment of bronchiolitis associated with respiratory syncytial virus infection in infants. Pediatrics 1983; 72:613-8.

33 Committee on Infectious Diseases. Ribavirin therapy of respiratory syncytial virus. Pediatrics 1987;79:475-6.

34 Hall CB, McBride JT, Walsh EE, et al. Aerosolized ribavirin treatment of infants with respiratory syncytial infection. A randomized double-blind study. $N$ Engl J Med 1983;308:1443-7.

35 Barry W, Cockburn F, Cornall R, Price JF, Sutherland G, Vardag A. Ribavirin aerosol for acute bronchiolitis. Arch Dis Child 1986;61:593-7.

36 Rodriguez WJ, Kim HW, Brandt CD. Aerosolized ribavirin in the treatment of patients with respiratory syncytial virus disease. Pediatr Infect Dis J 1987;6: 159-63.

37 Wald ER, Dashefsky B, Green M. In re ribavirin: A case of premature adjudication? J Pediatr 1988;112:154-8.

38 Conrad DA, Christenson JC, Waner JL, et al. Aerosolized ribavirin treatment of respiratory syncytial virus infection in infants hospitalized during an epidemic. Pediatr Infect Dis 1987;6:152-8.

39 Hall CB, McBride JT, Gala CL, et al. Ribavirin treatment of respiratory syncytial viral infection in infants with underlying cardiopulmonary disease. JAMA 1985; 254:3047-51.

40 Chanock RM, Richardson LS, Belshe RB, et al. Prospects for prevention of bronchiolitis caused by respiratory syncytial virus. Pediatr Res 1977;11:234-6.

41 Ogilvy MM. Maternal antibody and respiratory syncytial virus infection in infancy. $J$ Med Virol 1981;7:263-71. 